\title{
Determinants of Emerging Technology Commercialization: Empirical Evidences from MEMS Technology
}

\author{
Chunbo Wang ${ }^{1,2, *}$, Paulo Bento ${ }^{1}$, Lu Yin ${ }^{2}$ \\ ${ }^{1}$ University Institute of Lisbon, Lisbon, Portugal \\ ${ }^{2}$ School of Management and Economics, University of Electronic Science and Technology of China, Chengdu, China
}

\section{Email address:}

jack.wang@foxmail.com (Chunbo Wang), Paulo.Bento@iscte-iul.pt (P. Bento), YinLu@uestc.edu.cn (Lu Yin)

${ }^{*}$ Corresponding author

\section{To cite this article:}

Chunbo Wang, Paulo Bento, Lu Yin. Determinants of Emerging Technology Commercialization: Empirical Evidences from MEMS Technology. International Journal of Economic Behavior and Organization. Vol. 5, No. 6, 2017, pp. 124-130. doi: 10.11648/j.ijebo.20170506.12

Received: November 8, 2017; Accepted: November 17, 2017; Published: December 6, 2017

\begin{abstract}
Currently most of studies on commercialization of the emerging technology considered the context in developed countries like US, Japan, and EU with few research on developing country like China. To fill this gap, taking 112 Chinese Micro-Electro-Mechanical Systems (MEMS) enterprises as a sample, this thesis empirically investigated the determinants of emerging technology in China. Through multiple regression analysis, the empirical results show that technology property, market conditions, regional innovation network, and enterprise capability are main determinants of MEMS commercialization whereas social environment and policy and regulation do not have significant impact on the performance of MEMS commercialization.
\end{abstract}

Keywords: Emerging Technologies, Commercialization, Determinant, Micro-Electro-Mechanical Systems (MEMS)

\section{Introduction}

During the long history of society evolution, new technologies have gradually become the most important engine to economic growth, affecting the daily lives of all the people. Nowadays, they are mainly based on the development of information technology, Internet technology, biotechnology and other interdisciplinary areas with potential industrial applications. Recently, intelligent sensors, 3-dimension (3D) printing, nanotechnology, grapheme material, and biological information technology all have the potential to reshape the entire industries or create a new sector, updating the established business model completely [1].

Though emerging technologies have created opportunities for technological and economic innovation [2], their "creative destruction" characteristics also bring about a very high failure rate in their commercialization process [3]. Compared to the incremental technological innovation, emerging technology has a significant impact on the business model, posing new challenges to traditional managerial skills in an enterprise [3]. For emerging technology, the failures of incumbents are so widely recognized that some traditionally managerial approaches may turn to be a disadvantage when facing with outside entrants with new ideas and vision [4]. Therefore in order to increase the successful rates for both startups and incumbents, it is necessary to study the determinants of emerging technology commercialization.

In this study, a typical emerging technology namely Micro-Electro-Mechanical Systems (MEMS) is considered to explore the determinants of its commercialization process. MEMS technology is an edge technology building on micro-/nanotechnology including the design, processing, manufacturing, measurement and control of micro/nano materials. In its most general form, MEMS can be defined as miniaturized mechanical (micro/nano) and integrated circuit (IC) elements or, in other words, a technology consisting of microsensors, an information processing and signal-control circuit, micropower and micromechanical elements. All of them form a solid structure in which various data-interface entities and communication units integrated into a miniature intelligent device or system [5]. The technologies involved in MEMS are extremely complex (e.g., both sensors and actuators), draw upon a wide range of research fields (e.g., an interdisciplinary research area, including optical, mechanical, 
electrical, biological, and chemical research) and include a variety of products [6].

\section{Theoretical Background and Hypotheses}

The successful commercialization of an emerging technology cannot be guaranteed even though there is sufficient capital, human resources and land resources [7]. Innovation economics believes the success of commercialization is dependent on policy, market acceptance, technology track and dominant design, the perfection state of the innovation system and so on [8]. Among these factors, due to the characteristics of different technology, some factors may be critical to the commercialization success of a specific one. Having reviewed the literature on the factors affecting the commercialization of emerging technologies and taking into account the characteristics of MEMS technology, this paper suggest that the following six aspects might be the key factors that determine the success or failure of MEMS technology commercialization.

\subsection{Technology Property}

As [9] pointed out, the commercial prospects of an emerging technology are closely related to the characteristics of the emerging technology, including the following four properties: (1) technology development status like technology developing space and speed; (2) technology quality like he level of technologies and the wide range of applications; (3) technology opportunity i.e. whether emerging technologies can fill the gaps in the existing technology; and (4) technology difficulties, i.e., whether the main obstacles to the process of developing emerging technologies are clear and resolvable. The maturity of a technology is the basis and the primary condition for emerging technology commercialization.

Not all emerging technologies can be commercialized [4]. First, emerging technologies should have innovativeness and be in a leading position both at home and abroad. These types of technology can enhance the competitiveness of a country or an enterprise. Moreover, emerging technologies should have reached a certain mature level. Maturity refers not only to the technology but also to the market [10]. Finally, emerging technology should have operational and practical possibilities in the following three aspects: from concept to physical product, from business blueprint to production operation, from raw material to product. The analysis on MEMS technology shows that MEMS technology meets all the requirements for commercialization. In fact, MEMS is characterized by innovativeness, maturity and practicability has a comparatively high probability to achieve its commercialization [11]. Moreover, during this process, timing is also an important factors. Participation that is either too early or too late will causes the failure. One reason for the failure of MEMS companies is that they put immature products into immature markets too early [9]. Therefore, it is reasonable to propose the following hypothesis:

Hypothesis 1: There is a significant relationship between technology property and the performance of MEMS technology commercialization.

\subsection{Enterprise Capability}

MEMS technology heavily relies on professional equipment. Many MEMS enterprises cannot complete the whole processes from R\&D to pilot to scale production and final value creation due to the non-standardized producing procedure, strong intellectual property protection, large $\mathrm{R} \& \mathrm{D}$ investment, and long product developing. To address these problems, there is very high requirement for the MEMS enterprise's comprehensive management capabilities including its technology ability, financing ability, strategic management ability and even crisis management ability [12]. For MEMS technology, an enterprise's technology management ability and innovation ability is a core competence, determining its technology level, competitive advantage and future market position. Since MEMS technology commercialization requires huge investment in a series of processes [13], strong financing ability is key for an enterprise to quickly obtain necessary capital with low cost. Strategic management is the ability to determine an enterprise's market orientation and development direction, which determines the enterprise's long-term development prospects [14]. As with most products, marketing strategy is needed when MEMS technology enter the market. In a dynamic context, decision makers should adapt to the new environment by continuously improving their responses to external environment changes according to enterprise's own developing phase and resources. In addition, they should develop a more flexible organizational structure in response to adapt to the technological property and the market. Accordingly, the following hypothesis is proposed.

Hypothesis 2: There is a significantly positive relationship between enterprise capacity and the commercialization performance of MEMS technology

\subsection{Regional Innovation Network}

Due to the limited resources and capabilities, it is necessary to depend on the regional innovation network to acquire needed knowledge and supports [15]. As [16] suggested, a regional innovation network is a network system that is selectively established with the help of government, other enterprises, universities, research institutes and other organizations engaged in technology development, production and sales, in which various networks cooperate and coevolve each other to provide rich resources for the regional enterprises especially the startups [17]. For instance, the network formed by enterprises and intermediaries, banks, venture capital and other institutions establishes a technical innovation service network. The supply of raw materials, product manufacturing and sales networks established by the enterprise, the upstream suppliers and downstream customers form a market trade network [18]. Thus the regional 
innovation network is a dynamic and open innovation network system involving multiple participation and innovative resources. Among them, universities and research institutions, enterprises, government and intermediary organizations with innovative functions are the four most important agents in the innovation network [15]. Any commercialization of technology cannot be separated from the industry's structure, labor productivity and support or from the influence of factors such as capital, technology and personnel [13].

As discussed before, MEMS is a complex technology with very long industrial chain, requiring a large number of enterprises and the public sector to provide relevant supplementary technologies, assets or facilities [4]. The providers of these resources and their relationships constitute a supportive environment for MEMS commercialization (including supplementary facilities, supplementary technologies and related systems that support the development of emerging technology). As a type of radical innovation, MEMS technology commercialization is particularly influenced by production equipment, financial support, leading enterprises and scientific research institutions. Accordingly, to achieve MEMS commercialization, the structure of the industry and the resources, personnel, capital and technology are all important factors. However, as is well known, it is difficult for individual firm to obtain all of them, making the external supports critical to the commercialization [17]. Therefore, the following hypothesis is proposed:

Hypothesis 3: There is a significantly positive relationship between the completeness of the regional innovation network and the commercialization performance of MEMS technology.

\subsection{Market Conditions}

Market factors primarily include potential demands and competitive relationships. Emerging technology has to combine with market demand to complete the entire commercialization process [19]. One of the greatest uncertainties to emerging technology commercialization is the uncertainty of market demand, which is directly associated with the possibility of the final commercialization. Although an emerging new technology always fill the gap between the demand of a niche market and producers, it is still faced with many challenges during the product developing process [20]. Generally speaking, it is a long ways to make the emerging technology popular. Whether the MEMS technology can be successfully launched to the market, the final decision is the market, i.e. the choice of consumers. Only those goods that can meet consumer demand can gain market share and obtain profit, realizing their commercial values. Therefore, the ultimate goal of MEMS commercialization is to let the market and consumers accept and obtain rich economic benefits. In other words, market factors play a decisive role in the commercialization of emerging technologies [15] [18]. Thus the following hypothesis is proposed.
Hypothesis 4: There is a significantly positive relationship between market conditions and the commercialization performance of MEMS technology.

\subsection{Policy and Regulation}

Political and regulatory factors can generally be divided into two parts: one involves the government policies that relates to an industry's technology and its development for an emerging technology; another includes relevant laws and regulations that restrict and protect the industry's development [12] [15]. Though MEMS commercialization has a huge impact on the social economy, it is still faced with many obstacles like huge initial investment as well as very high market risk Therefore, the state and local government will play an important role on this commercialization process [11] [17]. For example, government may provide some financial supports to R\&D and preferential tax to MEMS firms. It is also necessary for local government to proactively establish regional innovation network. On the other hand, to cultivate fair and transparent marking environment, some regulation laws are also needed to avoid the unfair competition like IPR (Intellectual Property Right) protection. Accordingly, this study puts forward the following hypothesis:

Hypothesis 5: There is a significantly positive correlation between completeness of policy and regulation and the commercialization performance of MEMS technology.

\subsection{Social Environment}

Social environment refers to an organization's social context, cultural traditions, values, religious beliefs, educational standards and customs [17]. The elements of the social environment primarily include population, age structure, education and cultural level, and values. To some extent, the social environment in which the enterprise is located may affect the economic environment [18] [20]. For example, the population will directly affect the market capacity of a country or region [11]; the age structure also plays a decisive role in the type of product offered and how it is promoted [10]; the education and living habits will impact the level of demand for the product [11]; the social value affects the business goals, business activities and product recognition [21]. Therefore, in this study, the following hypothesis is proposed:

Hypothesis 6: There is a significant relationship between social environment and the commercialization performance of MEMS technology.

\section{Research Design}

\subsection{Questionnaire Design}

To examine the proposed six hypotheses, in this thesis, questionnaire was designed to empirically investigate the necessary data and information. In order to ensure the validity and reliability of measurement tools, based on the existing empirical research, the questionnaire is first designed 
with matured items used by Chinese and foreign scholars and then according to the background and purpose of this study, some measure index were added to form the first draft of the questionnaire. Then the draft questionnaire was tested by several management experts and mid-level and senior managers and was revised based on their various recommendations.

Then eight experts including three MEMS technology experts, two management professors and three Ph.D. candidates in management were invited to further revise the questionnaire. Next, two middle and senior managers from an MEMS enterprise were invited to conduct semantic analysis and revision, and then another expert on business management is invited to further revise and review all the items in the questionnaire. To eliminate the design flaws in the questionnaire before launching the large-scale survey, executives from five MEMS enterprises in Suzhou Nano Science and Technology Park were employed to perform the first pre-test. In-depth interviews and questionnaire were completed by the same person. All interviewees were asked to finish the questionnaire before the interview in order to check whether the questionnaire can reflect their thoughts truly and completely. Each respondent behavior was carefully observed and his or her questions and disagreements were recorded. Finally, a short conversation with the respondent was conducted to ask for their opinions on the questionnaire content and format.

This pre-test primarily examined the time required to complete the questionnaire, the clarity of the textual expression and the reasonableness of the questions. With respect to specific questions, the pre-survey helped us identify the missing issues related to research content (e.g., information on the technology inventor), questions that were prone to cause either misunderstanding or an incomplete understanding because of their complexity (e.g., asking the respondents to describe changes in the value chain of the industry to which their enterprises belonged), and questions the respondents were unable or reluctant to answer (e.g., the definition of the innovativeness of the technology, the enterprise's ownership structure and shareholder information) Based on the feedback from the pre-survey, several open-ended questions were converted into multiple-choice questions (e.g., the professional background of the enterprise's general manager). The wording and content of approximately $25 \%$ of the questions were further clarified, and $15 \%$ of the original questions were removed after the discussions, whereas some questions that were not initially included were added (e.g., information about the technology inventor, intellectual property ownership, and financing).

\subsection{Sample Selection and Data Collection}

The aim of this study is to investigate the determinants of MEMS technology commercialization under Chinese environment. In China, there are four major agents involved in this commercialization process: (1) research institutes, including the Chinese Academy of Sciences, the Ministry of Industry and Information Technology, the Ministry of
Science and local research institutions; (2) universities consisting of relevant faculty and research groups; (3) state-owned enterprises and the military companies, primarily including the China Electronics Technology Group, China Aerospace Science and Technology Corporation, China Aviation Industry Corporation, China North Industries Group and China National Machinery Industry Corporation; and (4) related private enterprises, primarily located in Beijing, Jiangsu, Shanghai, Shanxi, Sichuan and other places. The MEMS technologies and products developed by the first three major organizations were not fully market-oriented and therefore unrepresentative.

Therefore, in this study, MEMS private enterprises were chosen as a sample to study the critical factors for MEMS commercialization. The list of MEMS enterprises was obtained from the MEMS branch of the China Semiconductor Industry Association and tried to contact their CEOs through telephone or email. Finally, 181 companies were willing to participate in the questionnaire survey and some executives even expressed their desires to in-depth interviews.

The large-scale survey was conducted in 2015, several survey teams were formed to send the questionnaires to 181 MEMS private companies. Finally 137 questionnaires was obtained, in which only 112 enterprises totally completed the questionnaires with $62.2 \%$ respondent rate. There were 15 questionnaires with missing data, which may attribute to their commercial confidentiality or other unknown reasons. Considering only top managers can have knowledge to finish this questionnaire, this valid rate is satisfying to us. All questionnaires were sent back through the following channels: (1) face-to-face answer; (2) email; (3) post office. Thus the sample size for this empirical study is 112 . Appendix 2 shows their names and websites.

The response rate to a questionnaire is usually related to its length, and written questionnaires typically have a rather low response rate. The questionnaire had a broad topic and required a long time to complete. Therefore, the following measures were taken to improve the response rate: (1) for face-to-face interview, an appropriate time was chosen when the respondents were free, e.g., at meeting intermissions or during teatime; and (2) for the online questionnaire, the respondents were followed up and reminded via phone calls and emails. On average, 2-3 reminder emails or 1-2 reminder calls were needed to collect a questionnaire. The whole investigation lasted more than three months from September to December.

\subsection{Reliability and Validity Test}

In this study, SPSS 19.0 is employed to analyze the reliability and validity of each dependent variable. The alpha coefficient reaches 0.876 and those of each variables are also more than 0.7 , indicating that the questionnaire has good internal consistency and the instrument has a certain degree of reliability. The KMO values of all of the variables in the questionnaire were more than 0.7 , and their levels of significance were less than 0.01 , which means that the factor 
analysis results are ideal and these data correlate and are effective.

\section{Results}

\subsection{Descriptive Statistics}

Based on the valid questionnaires from 112 companies, their profiles were analyzed. As shown in Table 1, more than half of enterprises are startups with less than 3 years and only $6.25 \%$ firms are more than 6 years, showing the MEMS commercialization is still at the very beginning phase in China.

Table 1. Descriptive statistics for each measurement variable $(N=112)$.

\begin{tabular}{lllll}
\hline Variables & Min & Max & Mean & S. D. \\
\hline 1. Risk reduction & 1.00 & 5.00 & 3.50 & .665 \\
2. Financial performance & 1.00 & 5.00 & 3.33 & .765 \\
3. Technology property & 1.00 & 5.00 & 3.64 & .635 \\
4. Enterprise capability & 1.00 & 5.00 & 3.15 & .646 \\
5. Regional innovation network & 1.00 & 5.00 & 3.64 & .677 \\
6. Market conditions & 1.00 & 5.00 & 3.68 & .654 \\
7. Policies \& regulations & 1.00 & 5.00 & 2.57 & .683 \\
8. Social environment & 1.00 & 5.00 & 3.02 & .552 \\
\hline
\end{tabular}

From Table 2, it is easy to find that the average value of each factor and the performance of emerging technologies are bigger than 3 except for policies and regulations. In the questionnaire, the value of 3 represents "agreement". Most respondents believe that technical factors, enterprise capabilities, the regional innovation network, the market factors, and the social environment can influence emerging technology commercialization.

Table 2. Pearson correlation coefficients among the variables.

\begin{tabular}{llllllll}
\hline Var. & $\mathbf{1}$ & $\mathbf{2}$ & $\mathbf{3}$ & $\mathbf{4}$ & $\mathbf{5}$ & $\mathbf{6}$ & $\mathbf{7}$ \\
\hline 1. Technology Pr. & 1 & & & & & & \\
2. Enterprise Ca. & $.43^{* *}$ & 1 & & & & & \\
3. Regional Inno. & $.38^{* *}$ & $.67^{* *}$ & 1 & & & & \\
4. Market Condit. & $.57^{* *}$ & $.31^{* *}$ & $.50^{* *}$ & 1 & & & \\
5. Policy \& Regu. & $.47^{* *}$ & $.23^{* *}$ & $.42^{* *}$ & $.38^{* *}$ & 1 & & \\
6. Social Environ. & $.27^{* *}$ & $.28^{* *}$ & $.33^{* *}$ & $.42^{* *}$ & $.34^{* *}$ & 1 & \\
7. Risk Reduction & $.48^{* *}$ & $.41^{* *}$ & $.39^{* *}$ & $.49^{* *}$ & $.28^{* *}$ & $.25^{* *}$ & 1 \\
8. Financial Per. & $.45^{* *}$ & $.39^{* *}$ & $.53^{*}$ & $.52^{* *}$ & $.24^{* *}$ & .14 & $.39^{* *}$ \\
\hline ** is significant at the 0.01 level. * is significant at the 0.05 level (2-tailed)
\end{tabular}

\subsection{Regression Analysis}

According to the above standards, there is a moderate intensity of multicollinearity between enterprise capacity and the social environment. Meanwhile, the correlation analysis shows that social environment is not related to corporate financial performance. Therefore in the following regression analysis, social environment variable was deleted to control the multicollinearity problem. Multiple regression analysis is used in this study. The results of correlation analysis suggests that all five independents variables are all related to risk reduction and financial performance. Then the regression analysis was used to further examine to what extent these variables affect the performance of MEMS technology commercialization. Table 3 and Table 4 report the corresponding regression results.

Table 3. Regression analysis results (dependent variable: risk reduction).

\begin{tabular}{|c|c|c|c|c|c|}
\hline \multirow{2}{*}{ Factor } & \multicolumn{2}{|c|}{ Non-standard coefficient } & \multirow{2}{*}{ St. Co. } & \multirow{2}{*}{ t value } & \multirow{2}{*}{ Sig. } \\
\hline & Beta & St. Error & & & \\
\hline 1. Te. & 0.335 & 0.332 & 0.390 & 2.760 & 0.000 \\
\hline 2. En. & 0.086 & 0.126 & 0.099 & 0.922 & 0.869 \\
\hline 3. Re. & 0.112 & 0.213 & 0.319 & 1.123 & 0.023 \\
\hline 4. Ma. & 0.347 & 0.235 & 0.375 & 2.758 & 0.012 \\
\hline 5. Po. & 0.138 & 0.126 & 0.142 & 1.325 & 0.679 \\
\hline
\end{tabular}

Table 4. Regression analysis results (dependent variable: risk reduction).

\begin{tabular}{llllll}
\hline \multirow{2}{*}{ Factor } & \multicolumn{2}{l}{ Non-standard coefficient } & \multirow{2}{*}{ St. Co. } & t value & \multirow{2}{*}{ Sig. } \\
\cline { 2 - 5 } & Beta & St. Error & & & \\
\hline 1. Te. & 0.333 & 0.346 & 0.352 & 2.394 & 0.000 \\
2. En. & 0.125 & 0.368 & 0.333 & 3.234 & 0.869 \\
3. Re. & 0.118 & 0.236 & 0.327 & 1.535 & 0.023 \\
4. Ma. & 0.327 & 0.098 & 0.335 & 1.979 & 0.012 \\
5. Po. & 0.089 & 0.086 & 0.097 & 0.083 & 0.679 \\
\hline
\end{tabular}

According to the empirical data, $\mathrm{H} 1, \mathrm{H} 3$, and $\mathrm{H} 4$ are supported while $\mathrm{H} 5$ and H6 were not supported with $\mathrm{H} 2$ partly supported. Table 5 summarizes the empirical results.

Table 5. Empirical results of the hypotheses.

\begin{tabular}{lllll}
\hline & Inde. Var. & De. Var. & Emp. Results & Conclusion \\
\hline \multirow{2}{*}{ H1 } & Tech. & Risk Re. & significant & \\
& Pro. & Fin. Per. & significant & supported \\
H2 & Ent. & Risk Re. & Not sig. & Partly \\
& Cap. & Fin. Per. & Significant & supported \\
& Reg. & Risk Re. & significant & \\
H3 & Net. & Fin. Per. & significant & \\
& Mar. & Risk Re. & significant & \\
H4 & Con. & Fin. Per. & significant & \\
& Pol. & Risk Re. & Not sig. & \multirow{2}{*}{ Not supported } \\
H5 & Reg. & Fin. Per. & Not sig. & \\
& Soc. & Risk Re. & Not sig. & \multirow{2}{*}{ Not supported } \\
H6 & En. & Fin. Per. & Not sig. & \\
\end{tabular}

\section{Discussion}

Technology property and market conditions all have significantly positive impacts on the commercialization performance of emerging technology. Therefore, to enhance the commercialization performance of emerging technologies, MEMS businesses should understand the MEMS technology thoroughly including the technological developing status, technology quality, technology opportunity as well as technological obstacle. The enterprises should continuously strengthen their technological innovation efforts and maintain a high level of technological superiority while keeping closely eyes on the market changes such as competitors' dynamics, customer demand and customer satisfaction. It is important that effective measurement should be developed to observe change of the customer demand especially the potential demand so as to increase the successful commercialization performance. The findings also highlight the characteristics of emerging technology like the high uncertainty on market and 
technological developing roadmap, making it difficult to predict the prospect of a specific product.

Enterprise capability has a certain degree of influence on the commercialization performance of emerging technologies, though it is weaker than the influences of technology property and market conditions. The findings suggest that there is a significant positive relationship between enterprise capability and corporate financial performance of emerging technology while not significant impact on risk reduction, showing that most risks of MEMS technology are difficult to control or even identify. Once an enterprise's capabilities related to $\mathrm{R} \& \mathrm{D}$, production and marketing reached a certain level, it may help the enterprise quickly complete the early stage of commercialization. However, at later stages, the enhancement of the enterprise's basic capabilities did not guarantee that innovation activities with a low success rate averted risks or enhance performance. Due to the complexity and uncertainty of the market demand, it is difficult to make a marketing strategy. Meanwhile many unpredicted factors like oversea competitors and government regulation may also influence the acceptance of emerging technology products. Faced with immature market, sometimes an individual company have to depend on other complementary enterprises to explore the market.

Regional innovation network has a significant influence on the commercialization performance of emerging technologies. To developing new products of emerging technology is a very complex process with increasing high risk especially at the final stage. In particular, MEMS technological products require multi-disciplinary crossover and the integration of knowledge from various fields. It is very difficult for individual enterprises to achieve synchronous development in all complementary technologies. In this sense, the traditional linear innovation model is no longer applicable. Therefore, the technological innovation networks from the cooperation among various parties such as ventures, government, universities, research institutes, and enterprises have particular roles in the commercialization process. One of distinct advantages for this innovation network is that in the face of an ever-changing external environment, it can reallocate resources within the network to decrease the uncertainty in the commercialization of emerging technologies, thus increasing the probability of successful commercialization. As a result of the coordination mechanisms within the network, MEMS companies can obtain the information, knowledge and funds necessary to engage in innovation activities and achieve resource complementation, benefit sharing and risk sharing among the parties. Meanwhile, the interviews found that successful MEMS companies such as Wuxi Meixin, Wuxi Bewis, and Shenzhen Ruishen are in the MEMS regional innovation network. In the regional innovation network, the operating costs of enterprises are reduced, and the probability of success of commercialization is enhanced through the division of labor and cooperation, knowledge spillover, and transfer.

Policy and regulation and the social environment have no significant impacts on the commercialization performance of emerging technologies. In terms of policy and regulation, the development pace and changes in market structure of emerging technologies made it difficult for government to make effective industrial policies to enhance the commercialization performance of emerging technologies. At the same time due to the complexity of MEMS technology, it is hard for government to provide some details regulations to control the risks that enterprises faced. Thus, they were unable to begin to have a significant influence on risk reduction and performance improvement in commercialization performance. In addition, in this study most of answers returned from overseas and have been working in science parks designed by the government. Their homogenous background may lead to the insignificant effect of social environmental factors on the commercialization performance of emerging technologies. More important, since nearly all the MEMS products are intermediate one, it is difficult for the answers to know whether the demography factors like age structure and living standard have any influence on the commercialization of MEMS technology.

\section{Conclusion}

In this study, based on the theoretical analysis, six factors including technology property, market conditions, regional innovation network, enterprise capability, policy and regulation, and social environment were proposed to be critical to emerging MEMS commercialization. Through the multi-regression analyses, the empirical study shows that the first four factors have significant relationships to the commercialization performance of MEMS technology. Among them, technology property, market conditions, regional innovation network were supported while enterprise capability was partly supported by empirical data in this study. Thus these four factors are main determinants of emerging technology commercialization while the last two factors: the policy and regulation, and social environment are not the determinants of MEMS commercialization.

\section{Acknowledgements}

This research was financially supported by University of Electronic Science and Technology of China (UESTC) University Institute of Lisbon (ISCTE-IUL), (Portugal) Joint Program of Doctor of Management (IDMGT).

\section{References}

[1] B. Masters, and P. Thiel, Zero to One: Notes on Startups, or How to Build the Future. United States: Crown Publishing Group, 2014, pp. 23.

[2] L. Yin, and M. Wang, Introduction of the Management of Emerging Technologies, Beijing: Science Press. 2010, pp. 45.

[3] G. S. Day, and P. J. H. Schoemaker, Wharton on Managing Emerging Technologies. Hoboken: John Wiley \& Sons, Inc., 2000, pp. 34-37. 
[4] H. Huang, Z. Zhang, "Commercialization Process Research of Emerging Technology Products Based on Disruptive Innovation: Example of Apple Inc." Chinese Science and Technology Forum, 2015, 2, pp. 37-42.

[5] W. C. Tian, The Principle, Design and Analysis of MEMS. Xi' an: Xidian University Press. 2009, pp. 23-28.

[6] W. K. Sung, M. Dalal, “A3MHz spoke gyrospope with wide bandwidth and large dynamic range," Proceedings of the IEEE International Conference on Micro Electro Me-chanical Systems. Hongkong, China, 2010, pp. 104-107.

[7] J. P. Andrew, and H. L. Sirkin, "From innovation to revenue generation," Harvard Business Review, 2004, 47(2), pp. 65-67.

[8] J. R. Bright, Practical Technology Forecasting, Austin: Technology Futures, Inc., 1970, pp. 23-35.

[9] L. C. Huang, and X. J. Yang, "An analysis of the evolutionary relationship between emerging technologies and new industry," Science \& Technology Progress and Policy, 2014, 31(3), pp. 72 .

[10] J. Wang, F. Ling, J. Tang, "Evaluation of emerging technology impact on future industry based on patents," Journal of Intelligence, 2015, 33(5), pp. 44-48.

[11] P. Li, X. Chen, "Nano technology identification based on patent citation coupling cluster," Journal of Intelligence, 2015, 34(5), pp. $35-40$

[12] C. Wang, Q. Su, "Analysis of the effects of policy measures on emerging technology evolution: a case study of $3 \mathrm{D}$ printing technology," Journal of Intelligence, 2016, 33(6), pp. 110-116.

[13] C. Bi, "Coevolution mechanism of emerging technology, emerging market and emerging industry, Science \& Technology," Progress and Policy, 2015, 32(11), pp. 45-49.
[14] D. Zhai, J. Xia, J. Zhang, Q. Li,, X. Feng, "Method of Weak signal identification based on emerging technology patents," Journal of Intelligence, 2015, 34(8), pp. 31-36.

[15] Z. He, and L. Rayman-Bacchus, "Cluster network and innovation under transitional economies: An empirical study of the Shaxi garment cluster," Chinese Management Studies, 2010, 4(4), pp. 360-384.

[16] P. Cooke, "Regional systems of innovation: An evolutionary perspective," Environment and Planning, 1998, 30, pp. 1563-1584.

[17] Z. He, L. Rayman-Bacchus, and Y. M. Wu, "Self-organization of industrial clustering in a transition economy: a proposed framework and case study evidence from China," Research Policy, 2011, 40, pp. 1280-1294.

[18] D. Ding, Z. Li, M. Hu, "Potential risks in the Development of Emerging Technologies and the Problems of Technology Governance," Chinese Soft Science, 2013, 6, pp. 62-70.

[19] L. Yuan, and S. L. Deng (1999), "A methodology for competitive advantage analysis and strategy formulation: an example in a transitional economy," European Journal of Operation Research, 199, pp. 118-119.

[20] Y. Zhang, The Competitive Technical Intelligence Methodology for Emerging Technology, Doctoral Dissertation, Management and Economics, Beijing Institute of Technology, 2016, pp. 78-83.

[21] L. Rayman-Bacchus, Z. He, "Assessing clustered SME practice towards environmental and social impact: a Bourdieusian approach," International Journal of Innovation and Sustainable Development, 2014, 8(2): 167-189. 